\title{
Effect of Post Isometric Relaxation with Deep Neck Flexor Exercise in Subacute Mechanical Neck Pain
}

\author{
Priyanka Chauhan', Pooja Attrey ${ }^{2}$, Anand Kumar Singh ${ }^{3}$ \\ ${ }^{1}$ Assistant Professor, Department of Physiotherapy, R P Inderaprastha Institute of Medical Sciences, Karnal \\ Haryana-132001, India. \\ ${ }^{2}$ Assistant Professor, Department of Physiotherapy, T.D.T.R DAV IP \& R, YAMUNANAGAR Haryana, India. \\ ${ }^{3}$ Assistant Professor, Department of Physiotherapy, School of Medical and Allied Sciences,
} G.D Goenka University, Sohna Road, Gurugram, Haryana-122103, India.

Corresponding Author: Anand Kumar Singh

\begin{abstract}
Background: Mechanical neck pain (MNP) is the most common type of pain confined in the posterior aspect of neck, also known as nonspecific or simple neck pain affecting two thirds of the general population at some time in their lives.

Prevalence: Neck pain is most common muscular skeletal condition affecting up to $70 \%$ of individual and $5 \%$ to $10 \%$ of adults having a disabling neck pain problem. Neck pain is more common in women than men. The prevalence of neck pain in the general population has been reported to be $15 \%$ for men and $23 \%$ for women.
\end{abstract}

Objectives of the Study:

- To find out the effect of Post Isometric Relaxation (PIR) along with Deep Neck Flexor (DNF) exercises in reducing pain and disability and improving ROM in patient with sub-acute mechanical neck pain.

- To find out the effect of Deep Neck Flexor exercise alone in reducing pain and disability and improving ROM in patient with sub-acute mechanical neck pain.

- To compare whether Post Isometric Relaxation (PIR) along with Deep Neck Flexor exercises or Deep Neck Flexor exercises alone are effective in reducing pain and disability and improving ROM in patient with sub-acute mechanical neck pain

Methods: Study included 30 patients with lateral epicondylitis between ages 30-50 years. The subjects were randomly divided into 2 groups: Group-A and Group-B. Group A $(n=15)$ was treated using Cyriax physiotherapy, group B $(n=15)$ was treated with movement with mobilization. Patients were treated for 3 times a week for 4 weeks. Outcome measures are NPRS (Numeric Pain Rating Scale) and DASH (The Disabilities of the Arm, Shoulder and Hand).

Results: The results of the study indicate that there were highly statistically significant improvement in functional disability on NDI, cervical lateral flexion(Right \& Left), rotation (Right \& Left) ROM and reduction in pain on VAS in Group-A as compared to Group-B. There was no significant difference observed when the groups were compared for cervical flexion and extension ROM.

Conclusion: From the result it is concluded that Post isometric relaxation with DNF exercise is effective in mechanical neck pain.

Keywords: Mechanical neck pain (MNP), Post Isometric Relaxation (PIR), Deep Neck Flexor (DNF) exercise

\section{INTRODUCTION}

Mechanical neck pain (MNP) is the most common type of pain confined in the posterior aspect of neck, also known as non specific or simple neck pain affecting two thirds of the general population at some time in their lives. $1,2,3$ 
Priyanka Chauhan et.al. Effect of post isometric relaxation with deep neck flexor exercise in subacute mechanical neck pain.

Mechanical neck pain is second to low back pain in its frequency and leads to significant disability in general population. 4,5 Neck pain as defined by Merskey is the pain "anywhere within the region bounded superiorly by superior nuchal line, inferiorly by an imaginary line, through the tip of first thoracic spinous and laterally by sagittal plane tangential to the lateral border of neck. ${ }^{3}$

On the basis of duration of pain, 'as categorized by the international association for the study of pain' the pain are defined as. ${ }^{6}$

1. Acute when lasts up to six weeks.

2. Sub acute when lasts from six weeks to three months and

3. Chronic when lasts for more than three months.(IASP 1986)

It is estimated that the osseoligamentous system contributes $20 \%$ to the mechanical stability of the cervical spine while $80 \%$ is provided by the surrounding neck musculature. The ligaments role in stabilization occurs mainly at end of range postures while muscle supply dynamic support in activities around the neutral and mid-range postures, which are commonly adopted during functional daily task. ${ }^{9}$

To prevent muscle from injury and dysfunction the individual needs to avoid undue mechanical stress while at the same time improves flexibility and stability in order to acquire greater tolerance to strain. 12

\section{PREVALENCE}

Neck pain is most common muscular skeletal condition affecting up to $70 \%$ of individual and $5 \%$ to $10 \%$ of adults having a disabling neck pain problem.16 Neck pain is more common in women than men.17 The prevalence of neck pain in the general population has been reported to be $15 \%$ for men and 23\% for women. 18 The prevalence of this condition increases with age and is highest in middle age. 17 Neck pain is a significant health problem not only for adults but also for the young. 22 It is commonly seen in a working age group of $18-50.2$

\section{ETIOLOGY}

Multiple studies have found strong evidence supporting relation between the development of neck pain and job exposure such as prolonged static load, irregular posture, high task difficulties and poor computer positioning. The poor posture is one of the greatest causes of neck pain in the absence of trauma and major injuries. ${ }^{14}$ The mechanical neck pain can result from any event or condition (e.g incorrect posture, ageing, and acute injury, congenital or developmental defects) which leads to altered joint mechanics or muscle structure or function. ${ }^{14}$

As there is three way link between the joint, muscles and central nervous system therefore it can conclude that muscular dysfunction will result in poor posture, which will cause additional strain and subsequently lead to mechanical neck pain and vice versa causing affection of the surrounding muscles. ${ }^{14}$ Excessive physical strain may cause micro trauma in connective tissue and physiological stress may result in increased muscular tension. ${ }^{21}$ Neck muscles, show a strong tendency to develop hypertonous and spasm and alter properioceptive input. ${ }^{10}$

In upper cross syndrome as imbalance of muscles developed with facilitation of the upper trapezius, levator scapulae, sternocleidomastoid and pectoral muscle as well as inhibition of deep neck flexors, lower trapezius and serratus anterior. ${ }^{12}$

These muscle imbalance and movement dysfunction may have direct effect on joint surfaces leading to joint degeneration which can be source of pain but actual cause of pain is secondary to muscle imbalance. ${ }^{13}$

\section{NEED OF THE STUDY:}

With increase understanding of limited range of motion and pain in patient with sub acute mechanical neck pain, 
refinement must be made in our ability to adequately lengthen the tight muscle and strengthen the weak muscle to improve range of motion (ROM) and decrease pain and disability. Not many studies were found wherein MET and DNF exercises were combined. The effects of MET and DNF exercise have been reported, but prior studies involved patients with chronic neck pain. The effect of this intervention on patient with sub acute mechanical neck pain has been inconsistent and not proven. Hence a need arises to find out whether post isometric relaxation when added with DNF exercises will show additional effects in the outcome measures during recovery for the subjects with sub acute mechanical neck pain than DNF exercises alone.

\section{PURPOSE:}

To study the effect of Post Isometric Relaxation along with Deep Neck Flexor exercises in improving pain, disability and $\mathrm{ROM}$ in sub acute mechanical neck pain patients.

\section{AIMS AND OBJECTIVES OF THE STUDY:}

- To find out the effect of Post Isometric Relaxation (PIR) along with Deep Neck Flexor (DNF) exercises in reducing pain and disability and improving ROM in patient with sub acute mechanical neck pain.

- To find out the effect of Deep Neck Flexor exercise alone in reducing pain and disability and improving ROM in patient with sub acute mechanical neck pain.

- To compare whether Post Isometric Relaxation (PIR) along with Deep Neck Flexor exercises or Deep Neck Flexor exercises alone are effective in reducing pain and disability and improving ROM in patient with sub acute mechanical neck pain.

\section{HYPOTHESIS}

\section{NULL HYPOTHESIS:}

There is no significant difference between the effect of Post Isometric Relaxation (PIR) along with DNF exercise and the effect of Deep Neck Flexor (DNF) exercise alone on pain, disability and ROM in patient with sub acute mechanical neck pain.

\section{RESEARCH HYPOTHESIS:}

There is significant difference between the effect of Post Isometric Relaxation (PIR) along with DNF exercise and the effect of Deep Neck Flexor (DNF) exercise alone on pain, disability and ROM in patient with sub acute mechanical neck pain.

\section{OPERATIONAL DEFINITIONS: Muscle Energy Technique:}

Greenman described Muscle energy technique (MET) as a manual medicine treatment procedure that involves the voluntary contraction of patient muscle in a precisely controlled direction at varying levels of intensity against a distinctly executed counter force applied by the operator. $^{35}$

\section{Post Isometric Relaxation:}

The term refers to the effect of subsequent relaxation experienced by a muscle or group of muscles, after brief periods during which an isometric contraction has been performed. It is one of the two forms of MET. ${ }^{12}$

\section{Deep Neck Flexor Exercise:}

Deep Neck Flexor exercise involves a slow and controlled craniocervical flexion action (chin tuck) to activate and endure DNF muscles (longus capitis and longus colli) to maintain an upright posture of the cervical spine. ${ }^{7,21,38,53}$

\section{MATERIALS AND METHODS Study Design \\ Comparative Study \\ Sampling Method \\ Convenient Sampling.}


Priyanka Chauhan et.al. Effect of post isometric relaxation with deep neck flexor exercise in subacute mechanical neck pain.

\section{Study Setting}

The study was conducted in the various hospitals in Karnal. (Haryana, INDIA)

\section{Selection Criteria}

\section{Inclusion Criteria-}

- Mechanical neck pain of sub acute duration( 6 weeks- 3 months). ${ }^{3}$

- $18-50$ years, both males and females. ${ }^{13}$

- Limitation of neck movement due to pain. $^{56}$

\section{Exclusion Criteria}

- Inflammatory, malignant and neurological conditions.

- Metabolic Disease.

- Neck pain radiating into arms and upper extremity.

- Neck pain associated with headache or facial pain.

- History of recent major trauma or fracture of the cervical spine.

- Diagnosed case of disc prolapse, stenosis, spondylolisthesis.

- Any deformity (e.g. torticollis, scoliosis)

- History of surgery of cervical spine.

- Patients who are taking analgesics.

\section{Sample Size}

30 patients who fulfilled the inclusion and exclusion criteria were randomly assigned to one of two groups with each group consisted of 15 patients.

\section{Informed Consent}

The subject who fulfilled the inclusion and exclusion criteria, were explained about the purpose of the study. The consent of the form were explained to them and taken from every subject before starting the procedure.

\section{Variables}

\section{Dependant Variables}

- Range of motion (ROM)

- Pain

- Functional disability

\section{Independent Variables}

- Post Isometric Relaxation Technique

- Deep Neck Flexor Exercise

\section{Operational Tools/Instrumentation}

- Universal Goniometer

- Visual Analog Scale (VAS)

- Neck Disability Index (NDI)

\section{PROCEDURE}

On the first visit the subjects were screened according to the inclusion and exclusion criteria then consent form was filled up by eligible subjects and after that they were randomly divided into two groups.

Group A $(\mathrm{n}=15)$ - Moist Heat Pack (MHP) + post isometric relaxation + Deep Neck Flexor (DNF) exercises.

Group B ( $\mathrm{n}=15)$ - Moist Heat Pack (MHP) + Deep Neck Flexor (DNF) exercise

The baseline measurement was taken for pain, functional disability and cervical ROM and repeated at the end of intervention period i.e. on 6th day.

\section{PROTOCOL}

1. Group A $(n=15)$ - MHP (Moist Heat Pack) + Post isometric relaxation technique + DNF exercise

2. Group B $(n=15)$ - MHP (Moist Heat Pack) + DNF exercise

Treatment Session- Once a day for 6 consecutive days

1. MHP was given in the supine lying position for 20 minutes.

\section{DNF exercise Protocol}

DNF exercises were performed by patient in supine lying position (as described by Peterson) without the use of biofeedback unit, Patients were asked to tuck the chin without lifting the head for $10 \mathrm{sec}$ hold repeated 10 times once a day for 6 days 52 , 43

\section{Post Isometric Relaxation Technique Protocol}

Post isometric relaxation technique was applied to upper trapezius, levator scapulae and pectoralis major muscles for 5 repetition using $20 \%$ of maximal isometric contraction for 7-10 sec. with complete relaxation of all element, the stretch is maintained for $30 \mathrm{sec}^{13,33}$ 
Priyanka Chauhan et.al. Effect of post isometric relaxation with deep neck flexor exercise in subacute mechanical neck pain.

\section{TREATMENT PROCEDURE}

Before starting the treatment in both groups MHP was given for 20 minutes.

Group A - This group received Post Isometric Relaxation technique and DNF exercises.

Post Isometric Relaxation for 3 muscles on both sides were given;

\section{Upper trapezius muscle}

2. Levator Scapulae muscle

3. Pectoralis major muscle

Group B- This group received only DNF exercises.

\section{Procedure of DNF exercise:}

Procedure: The patient was laid in supine position with the cervical spine in a neutral position. The patient instructed to tuck the chin without lifting head and flatten the curve of the neck by nodding the head (nodding ="yes" movement). This position was hold for $10 \mathrm{sec}$ for 10 repetitions. This task involved flexion of the cranium on the cervical spine while ensuring that the back of the head remains in contact with the supporting surface.

\section{OUTCOMES MEASURES}

Pre and post intervention assessment were taken for pain with VAS, functional disability with NDI and ROM with universal goniometer. Pre-intervention readings were taken on the first day prior to the treatment session and post intervention readings were taken on the last day of treatment i.e. on 6th day.

\section{Measurements of the pain}

The pain level was assessed with a VAS which is a $10 \mathrm{~cm}$ horizontal line ranging from zero (no pain) to ten (worst ever experiences or imaginable pain). Patients were instructed to place a mark on the line at a point indicating the intensity of pain they feel. 55

\section{Measurements of functional disability}

Functional disability can be assessed with the neck disability index questionnaire. NDI is a neck specific questionnaire. The instruction given to the patients was; when you read a sentence that describe you today, put a tick against it. If the sentence does not describe you, than leave the space blank and go onto the next one. The score of the NDI is the total no. of item checked i.e. from minimum of zero to maximum of 50.46

\section{Measurements of ROM}

Cervical ROM was measure using universal goniometer in a sitting position for flexion, extension, lateral flexion (side flexion) and rotation. 49

\section{DATA ANALYSIS}

The base line value were taken for cervical range of motion (CROM), Pain and functional disability on day one is preintervention and repeated at the end of intervention period i.e. on 6th day is post intervention. Data was tabulated on master chart. The data analysis was performed using SPSS software version 16.0. The inter group and intra group comparison were done.

Following Test were used:

Arithmetic Mean, Paired and Unpaired ' $T$ 'tests were used to determine the significant difference between the two groups.

The results were taken to be significant if $P$ value is smaller than $0.05(p<0.05)$. COMPARISION BETWEEN GROUP A AND GROUP B FOR FLEXION ROM

Unpaired T-Test for the variable flexion ROM between Group A and Group $B$ at 1st (pre intervention) 6th day (post intervention)

Table No: 1

\begin{tabular}{|l|l|l|l|l|}
\hline \multirow{2}{*}{ Unpaired T Test } & \multicolumn{3}{|c|}{ Flexion } \\
\cline { 2 - 5 } & \multicolumn{2}{|c|}{ Pre } & \multicolumn{2}{c|}{ Post } \\
\cline { 2 - 5 } & Group A & Group B & Group A & Group B \\
\hline Mean & 27.53 & 30.93 & 37.73 & 36.07 \\
\hline S.D. & 6.556 & 7.723 & 6.375 & 6.766 \\
\hline Unpaired T Test & 1.300 & 0.694 \\
\hline P value & 0.2042 & 0.4932 \\
\hline Table Value at 0.05 df 28 & 2.05 & 2.05 \\
\hline Result & Not-Significant & Not-Significant \\
\hline
\end{tabular}


Priyanka Chauhan et.al. Effect of post isometric relaxation with deep neck flexor exercise in subacute mechanical neck pain.

Unpaired T- Test was done between Group A and Group B to compare the differences between the Groups. The Tvalue for flexion ROM of pre intervention and post intervention (for both groups) were $1.300 \quad(p>0.05)$ and $0.694 \quad(p>0.05)$ respectively.

The result of the variable was not significant at 1 st day (pre intervention).The result on 6thday (post intervention) showed that there were no significant changes between the groups.

\section{COMPARISION BETWEEN GROUP A AND GROUP B FOR EXTENSION ROM}

Unpaired T-Test for the variable extension ROM between Group A and Group B at 1st (pre intervention) 6th day (post intervention)

Table No: 2

\begin{tabular}{|l|c|c|c|c|}
\hline \multirow{2}{*}{ Unpaired T Test } & \multicolumn{3}{|c|}{ Extension } \\
\cline { 2 - 5 } & \multicolumn{2}{|c|}{ Pre } & \multicolumn{2}{c|}{ Post } \\
\cline { 2 - 5 } & Group A & Group B & Group A & Group B \\
\hline Mean & 28.67 & 29.93 & 39.20 & 36.87 \\
\hline S.D. & 5.640 & 6.777 & 6.304 & 6.728 \\
\hline Unpaired T Test & \multicolumn{2}{|c|}{0.556} & \multicolumn{2}{c|}{0.980} \\
\hline P value & \multicolumn{2}{|c|}{0.5823} & \multicolumn{2}{c|}{2.3354} \\
\hline Table Value at 0.05 df 28 & \multicolumn{2}{|c|}{2.05} & Not-Significant \\
\hline Result & Not-Significant \\
\hline
\end{tabular}

Unpaired T- Test was done between Group A and Group B to compare the differences between the Groups. The Tvalue for extension ROM of pre intervention and post intervention (for both groups) were $0.556(\mathrm{p}>0.05)$ and $0.980 \quad(\mathrm{p}>0.05)$ respectively. The result of the variable was not significant at $1 \mathrm{st}$ day (pre intervention).The result on 6thday (post intervention) showed that there were no significant changes between the groups

COMPARISION BETWEEN GROUP A AND GROUP B FOR RIGHT SIDE LATERAL FLEXION ROM

Unpaired T-Test for the variable right side lateral flexion ROM between Group A and Group B at 1st (pre intervention) 6th day (post intervention)

Table No: 3

\begin{tabular}{|c|c|c|c|c|}
\hline \multirow{2}{*}{ Unpaired T Test } & \multicolumn{3}{|c|}{ Lateral Flexion(Rt) } \\
\cline { 2 - 5 } & \multicolumn{2}{|c|}{ Pre } & \multicolumn{2}{c|}{ Post } \\
\cline { 2 - 5 } & Group A & Group B & Group A & Group B \\
\hline Mean & 28.27 & 29.00 & 40.33 & 31.00 \\
\hline S.D. & 6.563 & 6.772 & 4.776 & 6.547 \\
\hline Unpaired T Test & \multicolumn{2}{|c|}{0.301} & \multicolumn{2}{c|}{4.461} \\
\hline P value & \multicolumn{2}{|c|}{0.7655} & \multicolumn{2}{c|}{2.0001} \\
\hline Table Value at 0.05 df 28 & \multicolumn{2}{|c|}{2.05} & \multicolumn{2}{c|}{ Significant } \\
\hline Result & \multicolumn{2}{|c}{ Not-Significant } & \multicolumn{2}{c}{} \\
\hline
\end{tabular}

Unpaired T- Test was done between Group A and Group B to compare the differences between the Groups. The Tvalue for right side lateral flexion ROM of pre intervention and post intervention (for both groups) were 0.301 ( $\mathrm{p}>0.05)$ and 4.461 $(\mathrm{p}<0.05)$ respectively. The result of the variable was not significant at 1 st day (pre intervention).The result on 6thday (post intervention) showed that there were significant changes between the groups.

COMPARISION BETWEEN GROUP A AND GROUP B FOR LEFT SIDE LATERAL FLEXION ROM

Unpaired T-Test for the variable left side lateral flexion ROM between Group A and Group B at 1st (pre intervention) 6th day (post intervention) 
Priyanka Chauhan et.al. Effect of post isometric relaxation with deep neck flexor exercise in subacute mechanical neck pain.

Table No: 4

\begin{tabular}{|c|c|c|c|c|}
\hline \multirow{2}{*}{ Unpaired T Test } & \multicolumn{3}{|c|}{ Lateral Flexion(Lt) } \\
\cline { 2 - 5 } & \multicolumn{3}{|c|}{ Pre } & \multicolumn{2}{c|}{ Post } \\
\cline { 2 - 5 } & Group A & Group B & Group A & Group B \\
\hline Mean & 24.73 & 29.20 & 37.80 & 31.73 \\
\hline S.D. & 5.922 & 6.120 & 5.621 & 6.766 \\
\hline Unpaired T Test & \multicolumn{2}{|c|}{2.031} & \multicolumn{2}{c|}{2.671} \\
\hline P value & \multicolumn{2}{|c|}{0.0518} & \multicolumn{2}{c|}{0.0125} \\
\hline Table Value at 0.05 df 28 & \multicolumn{2}{|c|}{2.05} & \multicolumn{2}{c|}{2.05} \\
\hline Result & Not-Significant & \multicolumn{2}{c}{ Significant } \\
\hline
\end{tabular}

Unpaired T- Test was done between Group A and Group B to compare the differences between the Groups. The Tvalue for left side lateral flexion ROM of pre intervention and post intervention (for both groups) were 2.031 ( $\mathrm{p}>0.05)$ and 2.671 $(p<0.05)$ respectively. The result of the variable was not significant at 1 st day (pre intervention). The result on 6thday (post intervention) showed that there were significant changes between the groups.

COMPARISION BETWEEN GROUP A AND GROUP B FOR RIGHT SIDE ROTATION ROM

Unpaired T-Test for the variable right side rotation ROM between Group A and Group B at 1st (pre intervention) 6th day (post intervention)

Table No: 5

\begin{tabular}{|c|c|c|c|c|}
\hline \multirow{2}{*}{ Unpaired T Test } & \multicolumn{4}{|c|}{ Rotation (Rt) } \\
\cline { 2 - 5 } & \multicolumn{2}{|c|}{ Pre } & Group A & Group B \\
\cline { 2 - 5 } & Group A & Group B & 53.80 & 38.40 \\
\hline Mean & 39.33 & 35.53 & 7.457 & 9.311 \\
\hline S.D. & 9.955 & 9.606 & \multicolumn{2}{c|}{5.000} \\
\hline Unpaired T Test & \multicolumn{2}{|c|}{1.064} & \multicolumn{2}{c|}{$<0.001$} \\
\hline P value & \multicolumn{2}{|c|}{0.2965} & \multicolumn{2}{c|}{2.05} \\
\hline Table Value at 0.05 df 28 & \multicolumn{2}{|c|}{2.05} & Significant \\
\hline Result & \multicolumn{2}{c}{ Not-Significant } \\
\hline
\end{tabular}

Unpaired T- Test was done between Group A and Group B to compare the differences between the Groups. The Tvalue for right side rotation ROM of pre intervention and post intervention (for both groups) were $1.064(\mathrm{p}>0.05)$ and 5.000 $(p<0.05)$ respectively. The result of the variable was not significant at 1 st day (pre intervention).The result on 6thday (post intervention) showed that there were significant changes between the groups

\section{COMPARISION BETWEEN GROUP A AND GROUP B FOR LEFT SIDE ROTATION ROM}

Unpaired T-Test for the variable left side rotation ROM between Group A and Group B at 1st (pre intervention) 6th day (post intervention)

Table No: 6

\begin{tabular}{|c|c|c|c|c|}
\hline \multirow{2}{*}{ Unpaired T Test } & \multicolumn{4}{|c|}{ Rotation (Lt) } \\
\cline { 2 - 5 } & \multicolumn{3}{|c|}{ Pre } & \multicolumn{2}{c|}{ Post } \\
\cline { 2 - 5 } & Group A & Group B & Group A & Group B \\
\hline Mean & 41.53 & 36.67 & 54.80 & 39.87 \\
\hline S.D. & 7.337 & 8.095 & 5.609 & 8.651 \\
\hline Unpaired T Test & \multicolumn{2}{|c|}{1.725} & \multicolumn{2}{c|}{5.610} \\
\hline P value & \multicolumn{2}{|c|}{0.0955} & \multicolumn{2}{c|}{$<0.001$} \\
\hline Table Value at 0.05 df 28 & \multicolumn{2}{|c|}{2.05} & \multicolumn{2}{c|}{2.05} \\
\hline Result & \multicolumn{2}{|c|}{ Not-Significant } \\
\hline
\end{tabular}

Unpaired T- Test was done between Group A and Group B to compare the differences between the Groups. The T- value for left side rotation ROM of pre intervention and post intervention (for both groups) were $1.725(\mathrm{p}>0.05) \quad$ and 
Priyanka Chauhan et.al. Effect of post isometric relaxation with deep neck flexor exercise in subacute mechanical neck pain.

$5.610(\mathrm{p}<0.05)$ respectively. The result of the variable was not significant at 1 st day (pre intervention). The result on 6thday (post intervention) showed that there were significant changes between the groups
COMPARISION BETWEEN GROUP A AND GROUP B FOR VISUAL ANALOG SCALE (VAS)

Unpaired T-Test for the variable VAS between Group A and Group B at 1st (pre intervention) 6th day (post intervention)

Table No: 7

\begin{tabular}{|c|c|c|c|c|}
\hline \multirow{2}{*}{ Unpaired T Test } & \multicolumn{3}{|c|}{ VAS } \\
\cline { 2 - 5 } & \multicolumn{2}{|c|}{ Pre } & \multicolumn{2}{c|}{ Post } \\
\cline { 2 - 5 } & Group A & Group B & Group A & Group B \\
\hline Mean & 7.27 & 6.53 & 1.80 & 4.53 \\
\hline S.D. & 1.033 & 1.246 & 0.775 & 1.187 \\
\hline Unpaired T Test & \multicolumn{2}{|c|}{1.755} & \multicolumn{2}{c|}{7.468} \\
\hline P value & \multicolumn{2}{|c|}{0.0902} & \multicolumn{2}{c|}{2.05} \\
\hline Table Value at 0.05 df 28 & \multicolumn{2}{|c|}{2.05} & \multicolumn{2}{c|}{ Significant } \\
\hline Result & \multicolumn{2}{|c|}{ Not-Significant } & \multicolumn{2}{c}{} \\
\hline
\end{tabular}

Unpaired T- Test was done between Group A and Group B to compare the differences between the Groups. The Tvalue for VAS of pre intervention and post intervention (for both groups) were $1.755(\mathrm{p}>0.05)$ and $7.468(\mathrm{p}<0.05)$ respectively. The result of the variable was not significant at $1 \mathrm{st}$ day (pre intervention). The result on 6thday (post intervention) showed that there were significant changes between the groups

COMPARISION BETWEEN GROUP A AND GROUP B FOR NECK DISABILITY INDEX (NDI \%)

Unpaired T-Test for the variable NDI between Group A and Group B at 1st (pre intervention) 6th day (post intervention)

\begin{tabular}{|c|c|c|c|c|}
\hline \multicolumn{5}{|c|}{ Table No: 8} \\
\hline \multirow[t]{3}{*}{ Unpaired T Test } & \multicolumn{4}{|c|}{ NDI (\%) } \\
\hline & \multicolumn{2}{|c|}{ Pre } & \multicolumn{2}{|c|}{ Post } \\
\hline & Group A & Group B & Group A & Group B \\
\hline Mean & 52.37 & 48.69 & 14.10 & 40.90 \\
\hline S.D. & 11.034 & 9.173 & 6.626 & 8.391 \\
\hline Unpaired T Test & \multicolumn{2}{|c|}{0.991} & \multicolumn{2}{|c|}{9.708} \\
\hline $\begin{array}{c}\mathrm{P} \text { value } \\
\end{array}$ & \multicolumn{2}{|c|}{0.3300} & \multicolumn{2}{|c|}{$<0.001$} \\
\hline Table Value at 0.05 df 28 & \multicolumn{2}{|c|}{2.05} & \multicolumn{2}{|c|}{2.05} \\
\hline Result & \multicolumn{2}{|c|}{ Not-Significant } & \multicolumn{2}{|c|}{ Significant } \\
\hline
\end{tabular}

Unpaired T- Test was done between Group A and Group B to compare the differences between the Groups. The Tvalue for NDI of pre intervention and post intervention (for both groups) were 0.991 $(p>0.05)$ and $9.708(p<0.05)$ respectively. The result of the variable was not significant at 1st day (pre intervention). The result on 6thday (post intervention) showed that there were significant changes between the groups

\section{RESULTS}

The data was statistically analyzed by using paired $\mathrm{T}$-Test within group analysis and un-paired T-Test for inter group analysis.

The results showed that there were no significant differences in demographic variables (i.e. age, gender distribution) and base line characteristics between the groups $(p>0.05)$ thus, homogeneity between the both groups were maintained.

There were no significant differences in cervical ROM, VAS and NDI scores between Group-A and Group-B on 
pre-intervention (1st Day). The level of significance selected for the study was $\mathrm{p}$ smaller than $0.05(\mathrm{p}<0.05)$.

Paired T-Test for the pre and post intervention comparison within group analysis revealed a significant improvement in ROM, VAS and NDI values for both groups $(\mathrm{p}<0.05)$.

However, on comparison of both groups (Group-A: Post isometric relaxation with DNF exercise and Group-B: DNF exercise only) the results of the study indicate that there were highly statistically significant improvement in functional disability on NDI, cervical lateral flexion (Right \& Left), rotation (Right \& Left) ROM and reduction in pain on VAS in Group-A as compared to Group-B. There was no significant difference observed when the groups were compared for cervical flexion and extension ROM.

\section{DISCUSSION}

The aim of this study was to compare the effect of two intervention i.e. post isometric relaxation along with DNF exercise (Group A) versus only DNF exercise (Group B) on pain, functional disability and cervical ROM in patient with sub-acute mechanical neck pain.

As per statistical analysis of the data, there was significant improvement in cervical ROM and functional disability and reduction in pain in both groups after receiving their respective treatment.

When compared, post isometric relaxation with DNF exercise (Group-A) showed more reduction in pain and more improvement in functional disability and cervical lateral flexion and rotation ROM than only DNF exercise group. However for cervical flexion and extension ROM there was almost equal improvement in both groups.

The reduction in pain and improvement in functional disability and ROM in DNF exercise group (Group-B) may be due to stabilization of cervical spine in all positions against the gravity by DNF muscles which form a muscular sleeve and structurally supports cervical motion segments. ${ }^{7,45}$ As weak neck flexor muscles reduce the ability to maintain upright cervical posture 50 whereas DNF exercises directly activate the DNF musculature which has high density muscle spindle and improve the cervical kinesthetic sense. ${ }^{52}$ The improved cervical posture because of DNF exercise may have an additional long term benefit of reducing recurrent episodes of neck pain. ${ }^{52}$

This study results were supported by the study of Amer Almaz Abdel-Aziem et al on neck pain who concluded that DNF exercise with physical therapy agents showed significant improvement in pain, functional disability and cervical ROM. ${ }^{52}$

This study was also supported by the study conducted by Vijay Kage et al who concluded improvement in CROM in DNF strengthening exercise group. ${ }^{43}$

The findings of this study were also similar with the findings of Yadav $\mathrm{H}$. who found DNF training effective in reducing pain, improvement in functional disability and CROM in mechanical neck pain. ${ }^{33}$

For long duration a fixed head and neck posture causes shortening of posterior muscles and lengthening of anterior neck muscles. ${ }^{33}$ As post isometric relaxation is useful when muscle tightness or shortness is major contributing factor to somatic dysfunction 17 therefore PIR for stretching of tight muscles were included with strengthening of DNF muscles in Group-A

In Group-A there were more reduction in pain had seen might be due to additive effects of PIR which involve stretching and isometric contraction simultaneously stimulate the muscle and joint mechanoreceptor and proprioceptors which in turn reduce the sensation of pain. ${ }^{13}$ The possible mechanism for the reduction in pain in PIR group can be explained by the inhibitory Golgi tendon reflex, activated during the isometric contraction that leads to reflex relaxation of muscle. ${ }^{12,33}$

There was statistically significant difference found in NDI scores in the treatment groups. This could be because of 
the NDI assesses different aspects of neck pain which include pain intensity, daily activities which suggests that improvement in the NDI score might be due to reduction in pain. As Group A showed more reduction in pain that may results in overall improvement in functional disability of the patients.

The effects of post isometric relaxation for increase in ROM post intervention can be explained on the basis of physiological mechanisms behind the changes in muscle extensibility - reflex relaxation, viscoelastic change and changes to stretch tolerance. 3

The Group-A showed more improvement in lateral flexion (Right \&Left) and rotation (Right \& Left) ROM might be due to stretching of postural muscles i.e. upper trapezius and levator scapulae. The reason of almost equal improvement in flexion ROM in both groups due to cranio cervical flexion which is the principal action of DNF muscle.

The effect of moist heat pack cannot be overlooked. Moist heat therapy is known to have effects on pain and spasm it causes pain reduction and improved tissue extensibility in both groups. ${ }^{3}$

The results of post isometric relaxation group were consistent with the results of Gupta et al who evaluated the efficacy of PIR in patients with non specific neck pain and they concluded that PIR may be more effective in reducing pain and disability and increasing cervical ROM in patient with non specific neck pain. ${ }^{10}$ The results of this study were also supported by a study by Abha and Angu Samy who compared PIR with integrated neuromuscular inhibition technique on upper trapezius trigger points and concluded that PIR is effective in reducing pain and improving functional status. ${ }^{37}$ The results of study were also consistent with result of study done by Haritha et al who concluded that PIR technique group had better improvement in ROM, neck functional activities and reduction of pain in patients with chronic non specific neck pain. ${ }^{17}$
The study of Wilson et al who found MET to be effective in decreasing disability in acute low back pain also supported this study. ${ }^{35}$ The results of this study were supported by the study of Mahajan et al which concluded that MET showed improvement in pain, functional status and cervical lateral flexion and rotation ROM in patients with sub acute mechanical neck pain. ${ }^{3}$ The study carried out by Phadke et al on effects of MET and static stretching in patients with mechanical neck pain showed that MET group had better improvement in pain and function status of patients with mechanical neck pain. ${ }^{13}$

The significant improvement in reduction of pain, functional disability and ROM in group-A who received post isometric relaxation combined with DNF exercises as compared to Group-B who received DNF exercise alone supported by a study by Narang $S$. et al who found that MET combined with DNF exercise was more effective than DNF exercise alone in improving pain and decreasing disability and correcting forward head posture. ${ }^{21}$

In this study we included both strengthening of DNF muscles and stretching of tight muscles in Group-A thus, the combined benefits of post isometric relaxation and DNF exercise result in greater reduction in pain and disability and improved lateral flexion and rotation ROM in patients with sub acute mechanical neck pain as compared to Group-B where DNF exercise was given only in patients with sub acute mechanical neck pain.

\section{CONCLUSION}

The present study concluded that post isometric relaxation along with Deep Neck Flexor exercise are more effective than Deep Neck Flexor exercise alone in reducing pain and disability and improvement in Cervical ROM in patients with sub acute mechanical neck pain. As this study demonstrated that both groups showed improvements in outcomes measures but the group given treatment of post isometric relaxation with Deep Neck 
Priyanka Chauhan et.al. Effect of post isometric relaxation with deep neck flexor exercise in subacute mechanical neck pain.

Flexor exercise showed significant improvements in cervical ROM and reducing pain, functional disability. Hence the research hypothesis which state that "There is significant difference between the effect of post isometric relaxation along with DNF exercise and the effect of DNF exercise alone on pain, disability and ROM in patients with sub acute mechanical neck pain" has been accepted.

\section{Limitations}

1. Sample size was small and might not be representative for whole population.

2. The protocol of the study was also small duration which consisted of six days only.

3. No follow-up was taken to see the long term effect of the treatment due to non availability of the patients.

4. This study included a heterogeneous group which consisted of both females and males.

\section{Acknowledgement: None}

\section{Conflict of Interest: None}

\section{Source of Funding: None}

\section{Ethical Approval: Approved}

\section{REFERENCES}

1. Binder Al. Cervical spondylosis and neck pain. BMJ. 2007; 334: 527-31.

2. Peeyoosha Nitsure, Aarty Welling. Effect of gross myofascial release of limb and neck on pain and function in subjects with mechanical neck pain with upper limb radiculapathy- A clinical trial. Int $\mathbf{J}$ Dent Med Res. 2014; 1(3): 8-16.

3. Mahajan R, Kataria C, Bansal K. Comparative effectiveness of muscle energy technique and static stretching for treatment of subacute mechanical neck pain. International Journal of health and rehabilitation sciences. 2012; 1(1): 16-24.

4. Megan M.Heintz, Eric J Hegedus. Multimodal management of mechanical neck pain using a treatment based classification system. The Journal of manual and manipulative therapy. 2008; 16(4): 217224.

5. Borisut S, Vongsirinavarat $\mathrm{M}$, Vachalathiti $\mathrm{R}$, Sakulsriprasert P. Effects of strength and endurance training of superficial and deep neck muscles on muscle activities and pain level of females with chronic neck pain. J. Phys. Ther Sci. 2013; 25(9): 1157-1162.

6. Salo P. Assessing physical Capacity, Disability and Health Quality of life in neck pain. Studies in sport, physical education and health. 2010; 156: 1-105.

7. Kevin D Harris, Darren M Heer, Tanja C Roy, Diane M Santos, Julie M Whitman, Robert S Wainner et al. Reliability of a measurement of neck flexor muscle endurance. Physical therapy. 2005; 85(12): 1349-1355.

8. P D Falla, G Jull, P Dall'Alba, A Rainoldi. An electromyographic analysis of deep cervical flexor muscles in performance of craniocervical flexion. Physical Therapy. 2003; 83(10): 899-906.

9. Falla D. Unravelling the complexity of muscle impairment in chronic pain. Man Ther, 2004; 9(3): 125-33.

10. S.Guptaet, P Jaiswal, D. Chhabra. A comparative study between post isometric relaxation and isometric exercises in nonspecific neck pain. Journal of Exercise Science and Physiotherapy. 2008; 4(2): 8894.

11. Cunha AC, Thomaz Nogueira Burke, Fábio Jorge Renovato França, Amélia Pasqual Marques. Effect of global posture reeducation and of static stretching on pain, range of motion and quality of life in women with chronic neck pain. A randomized clinical trial. Clinics. 2008; 63(6): 763-770.

12. Chaitow L. Muscle energy technique. Third ed. Churchill Livingstone. 2006; 3: 2,6, 8, 52, 59-60, 171-186.

13. Phadke A, Nilima Bedekar, Ashok Shyam, Parag Sancheti. Efffect of muscle energy technique and static stretching on pain and functional disability in patients with mechanical neck pain A randomized controlled trial. Hong Kong physiotherapy Journal. 2016; 35: 5-11.

14. Deepa, Abichandani; Dabholkar, Twinkle Y; Yardi, Sujata. Comparison of the efficacy of maitland thoracic mobilization and deep neck flexor endurance training in patients with mechanical neck pain. Indian 
Priyanka Chauhan et.al. Effect of post isometric relaxation with deep neck flexor exercise in subacute mechanical neck pain.

Journal of physiotherapy and occupational therapy. 2014; 8(3): 77-82.

15. Mechanical Pain Definition- spinehealth.com Glossary,www.spinehealth.com: $\quad$ https://www.spinehealth.com/glossary/mechanical -pain

16. Srilatha K. Kotteeswaran k. Effect of cervical muscle endurance training on cervical flexor and extensors in mechanical neck pain. IJBPAS. 2013; 2(9): 1755-1761.

17. Haritha P,Shanthi C,Madhavi K. Efficacy of Post isometric relaxation versus static stretching in subjects with chronic nonspecific neck pain. Int J. physiother. 2015; 2(6): 1097-1102.

18. Christina Gummeson,Sven-Olof Isacsson, Agneta H Isacsson, H Ingemar Andersson, John Ektor-Andersen, Per-Olof Östergren,Bertil Hanson. The transition of reported pain in different body regions - a one year follow up study. BMC Musculoskeletal Disorder. 2006; 7:17.

19. Steven P. Cohen. Epidemiology. Diagnosis and Treatment of Neck pain. Mayo clinproc 2015; 90(2): 284-299.

20. StephenEdmondston,GuðnýBjörnsdóttir,Th orvaldurPálsson HegeSolgård KasperUssing, GarryAllison. Endurance and Fatigue characteristics of the neck flexor and extensor muscles during isometric tests in patients with postural neck pain. Manual Therapy2011; 16(4): 332-338.

21. Sakshi N., Suman M. Geetanjali S. Effect of muscle energy technique and deep neck flexors exercise on pain, Disability and Forward head posture in patients with chronic neck pain. Indian Journal of physiotherapy and occupational therapy. 2014; 8(4): 43-48.

22. Zaheen Ahmed Iqbal, ReenaRajan, Sohrab Ahmed Khan, Ahmad H. Alghadir. Effect of deep cervical flexor muscles training using pressure biofeedback on pain and disability of school teachers with neck pain. J Phys. Ther. Sci. 2013; 25: 657-661.

23. Robert J. Kowalski, Ferrara, Lisa A, Benzel, Edward C. Biomechanics of the spine. Neurosurgery Quarterly. 2005; 15(1): 4259.

24. Pamela K. Levangie, C.C.Norkin. Joint structure and function-A comprehensive analysis 3rd edition. 2001; 3:114,130-137.

25. B.D. Chaurasia's. Human Anatomy regional and applied upper limb and Thorax. 2002; 1(3): $37,53,54$.
26. Gray H. Anatomy of the human body IV Myology The Anterior Vertebral Muscles, The muscles connecting upper extremity to the vertebral column, The muscles connecting the upper extremity to the anterior and lateral thoracicwalls. 1918; 20.

27. Manuel Saavedra-Hernández, Adelaida M. Castro-Sánchez, Manuel Arroyo-Morales, Joshua A. Cleland, Inmaculada C. LaraPalomo, César Fernández-de-las-Peñas, Short term effect of kinesio taping vesus cervical thrust manipulation in patients with mechanical neck pain A randomized clinical trial. Journal of Orthopaedic\& Sports Physical therapy. 2012; 42(8): 724-730.

28. Agrawal Sonal S. Comparison between post isometric relaxation and reciprocal inhibition maneuvers on hamstring flexibility in young healthy adults: Randomized clinical trial. Int. J Med Res Health Sci. 2016; 5(1): 33-37.

29. King of the Gym. Levator Scapulae: Functional anatomy guides (2015) By Alex. (Source-Online).

30. B.Cagnie, L. Danneels, De.Van Tiggelen, De Loose, D. Cambier. Individual and work related risk factor for neck pain among office workers: a cross sectional study. Eur Spine J. 2007; 16: 679- 686.

31. D.C Metgud, Khatri S, , Subhash Khatri, M. G. Mokashi, and P. N. Saha.

32. An ergonomic study of women in a woolen textile factory for identification of healthrelated problems. Indian Journal of Occupational and Environmental Medicine. 2008; 12(1): 14-19.

33. Cesar Fernandez-de-Laspenas, Joshua A. Cleland, Jan Dommerholt, Manual therapy for musculoskeletal pain syndromes-An evidence and clinical informed approach. 2016; 1(2): 9, 96-97.

34. Harshita Yadav, Manu Goyal. Efficacy of muscle energy technique and deep neck flexors training in mechanical neck pain-A randomized clinical trial. International Journal of Therapies and Rehabilitation Research. 2015; 4(1): 52-66.

35. Kwan-Woo Lee, Won-Ho Kim. Effect of thoracic manipulation and deep craniocervical flexor training on pain, mobility, strength, and disability of the neck of patients with chronic nonspecific neck pain: A randomized clinical trial. The Journal of Physical Therapy Science. 2016; 28(1): 175-180. 
Priyanka Chauhan et.al. Effect of post isometric relaxation with deep neck flexor exercise in subacute mechanical neck pain.

36. Capt. Eric Wilson, Otto Payton, Lisa Donegan-Shoaf, Katherine Dec. Muscle Energy Technique in patients with acute low back pain. A pilot clinical trial. Journal of Orthopaedic\& Sports Physical Therapy. 2003; 33(9): 502-514.

37. Lewit K, Simons DG. Myofascial pain: relief by post isometric relaxation. Arch Phys Med Rehabil. 1984; 65(8): 452-456.

38. Abha S, Angusamy R, Sumit Kalra, Sukhmeet Singh. Efficacy of post isometric relaxation versus integrated neuromuscular ischemic technique in the treatment of upper trapezius trigger points. Ind $\mathbf{J}$ Physiother\&OccupTher. 2010; 4: 1-5.

39. Jull GA, O'leary SP, Falla DL. Clinical assessment of the deep cervical flexor muscles: the craniocervical flexion test. J Manipulative PhysiolTher. 2008; 31(7): 525-533.

40. Pranjal Gogoi. Effect of the cervical endurance training program in mechanical neck pain. Int J Physiother. 2015; 2(5): 724730.

41. Falla D. Jull G, Hodges PW. Patients with neck pain demonstrate reduced EMG activity of deep cervical flexor muscles during performance of craniocervical flexion test. Spine 2004; 29(19): 21082114.

42. Misuk Cho, Hyunja Jeong, Byeongjun Hwangl. Effects of active and passive intervention programs applied to patient's neck on their muscular strengths, muscular endurance and joint range of motion. J Phys. Ther. Sci 2012; 24(3): 283-286.

43. Gwendolen Jull, Patricia Trott, Helen Potter, Guy Zito, Ken Niere, Debra Shirley, Jonathan Emberson, Ian Marschner, Carolyn Richardson. A randomized controlled trial of exercise and manipulative therapy for cervicogenic headache. Spine 2002; 27(17): 1835-1843.

44. Vijay Kage, Nishita Y. Patel, Mangala P. Pai. To compare the effect of deep neck flexors strenghtning exercise and mckenzie neck exercise in subjects with forward neck posture: A randomized clinical trial. Int $\mathbf{J}$ Physiother Res. 2016; 4(2): 1451-1458.

45. Yesim Dusunceli, Cihat Ozturk, Funda Atamaz, Simin Hepguler, Berrin Durmaz. Efficacy of neck stabilization exercise for neck pain- A randomized control study. J Rehab Med. 2009; 41(8): 626-631.
46. Bhuvan Deep Gupta, Shagun Aggarwal, Bharat Gupta, Madhuri Gupta, Neha Gupta. Effect of deep cervical flexor training versus conventional isometric training on forward head posture, pain, neck disability index in dentists suffering from chronic neck pain. Journal of Clinical and Diagnostic Research. 2013; 7(10): 2261-2264.

47. Vernon H, Mior S. The neck disability index: a study of reliability and validity. $\mathbf{J}$ Manipulative PhysiolTher. 1991; 14(7): 409-415.

48. Bijur PE, Silver W, Gallagher EJ. Reliability of visual analog scale for measurement of acute pain. AcadEmerg Med. 2001; 8(12): 1153-1157

49. Katherine L Whitcroft 1, Laura Massouh, Rouin Amirfeyz, Gordon Bannister. Comparison of methods of measuring active cervical range of motion. Spine. 2010; 35(19): E976-980.

50. Norkin CC, White DJ. Measurement of joint motion. A guide to goniometry. FA Davis Co. 1995; 2: 181-196.

51. Jeoung-Ah Ahn, Joong-Hwi Kim, Anthony L Bendik, Ju-Yong Shin. Effect of stabilization exercise with a swiss ball on neck- shoulder pain and mobility of adults with prolonged exposure to VDTs. J. PhysTher Sci. 2015; 27(4): 981-984.

52. David J. Magee. Orthopaedic physical Assessment. 2005; 4: 145- 154.

53. Amar Almaz Abdel-aziem, Amira HussinDraz. Efficacy of deep neck flexor exercise for neck pain. A randomized controlled study. Turk J Phys Med Rehab. 2016; 62(2): 107-115.

54. G A Jull, D Falla, B Vicenzino, P W Hodges. The effect of therapeutic exercise on activation of the deep cervical flexor muscles in people with chronic neck pain. Manual therapy. 2009; 14(6): 696-701.

55. Kotteeswaran K, Kumar C. Efficacy of muscle energy technique in mechanical low back pain. International Journal of Biology, Pharmacy and Allied Sciences. 2013; 2(9): 1725-1731.

56. Margretta Nordin, Eugene J. Carrage, Sheilah Hogg-Johnson, Shira Schecter Weiner, Eric L. Hurwitz, Paul M. Peloso, Jaine Guzman, Gabrielle Van Der Velde, Linda J.Carroll, Lena W. Sholm, Pierre Cote, J.David Cassidy and Scott Haldemanl. Assessment of neck pain and its associated disorders. Results of the bone and joint 
Priyanka Chauhan et.al. Effect of post isometric relaxation with deep neck flexor exercise in subacute mechanical neck pain.

decade 2000-2010 task force on neck pain and its associated disorders. Eur Spine J. 2008; 17(suppl 1)S101-S122.

57. Benozi Bohia,Abhijit Dutta, Biju Chetri. A comparative study to find out the effectiveness of muscle energy technique versus myofascial trigger point release of upper trapezius in mechanical neck pain.
Journal of Novel Physiotherapies. 2016; 6(3): 47.

How to cite this article: Chauhan P, Attrey P, Singh AK. Effect of post isometric relaxation with deep neck flexor exercise in subacute mechanical neck pain. Int J Health Sci Res. 2021; 11(10): 46-59. DOI: https://doi.org/10. 52403/ijhsr.20211008 